\title{
Comparison of Aerotolerant and Reference Strains of Campylobacter Species by Polyacrylamide Gel Electrophoresis
}

\author{
JOHN HANNA,* SYDNEY D. NEILL, JOHN J. O'BRIEN, AND WILLIAM A. ELLIS \\ Department of Agriculture, Veterinary Research Laboratories, Stormont, Belfast BT4 3SD, Northern Ireland
}

\begin{abstract}
Acid-phenol extracts of as-yet-unnamed aerotolerant Campylobacter sp. strains isolated from animal genitalia and fetuses were compared with extracts of reference strains of Campylobacter species by using polyacrylamide gel electrophoresis. The electrophoretic protein profiles confirmed the uniqueness of the aerotolerant isolates within the genus Campylobacter and provided a means of differentiation at the species level. The reproducibility of the results demonstrated the value of this technique in taxonomic studies.
\end{abstract}

Gram-negative helically curved bacteria have been associated with genital disease and abortion in animals since the early part of this century (19). These organisms were initially placed in the genus Vibrio (20), but subsequently they were placed in the genus Campylobacter (16). There are now two commonly used classifications of Campylobacter $(18,22)$, and this has contributed to much of the confusion that surrounds the terminology of these organisms in the medical and veterinary literature.

In our laboratory, helically curved gram-negative rods have been recovered from a high proportion of bovine, porcine $(2,3)$, ovine, and equine abortions (unpublished data). Initial attempts to isolate these organisms by using conventional methods for culturing Campylobacter species were unsuccessful (11). Characteristically, the isolates were aerotolerant after subculturing, and although they were assigned to the genus Campylobacter (12), they were serologically distinct from other species in this genus (3).

It is generally accepted that the tests currently used in classification studies of Campylobacter species have limitations and in some instances give unreliable results $(1,4)$. Electrophoretic studies carried out with acid-phenol (AP) extracts of campylobacters have indicated that this method is a more reliable taxonomic aid than the more commonly used biochemical tests $(4,10)$. In this paper we describe a study of the electrophoretic patterns of AP extracts of aerotolerant Campylobacter isolates and compare these patterns with those of reference strains of Campylobacter species.

\section{MATERIALS AND METHODS}

Organisms. The 41 aerotolerant Campylobacter isolates examined in this study included 25 strains from cattle, 9 strains from pigs, 5 strains from sheep, and 2 strains from horses. The reference strains of Campylobacter included 9 strains of Campylobacter fetus subsp. venerealis, 10 strains of $C$. fetus subsp. fetus (including 5 strains recently isolated from bovine feces), 10 strains of Campylobacter coli, 10 strains of Campylobacter jejuni, 3 strains of Campylobacter sputorum subsp. sputorum, 3 strains of $C$. sputorum subsp. mucosalis, and 4 strains of $C$. sputorum subsp. bubulus. (The reference cultures were obtained from the following sources: National Collection of Type Cultures, London, England; Collection of the Institut Pasteur, Paris, France; B. D. Firehammer, Montana State University, Bozeman; and G. H. K. Lawson, University of Edinburgh, Edinburgh, Scotland.) The reference strains were stored at $-70^{\circ} \mathrm{C}$, and the aerotolerant Campylobacter isolates were held in liquid nitrogen (11). Details concerning the campylobacter reference strains used in electrophoretograms (see Fig. 1 and 4) are given in Table 1.

Bacterial cell production. The aerotolerant Campylobacter isolates were cultured at $30^{\circ} \mathrm{C}$ in air for 2 days in semisolid Trypticase soy broth (BBL Microbiology Systems, Cockeysville, Md.) containing $0.75 \%$ agar, after which they were inoculated onto agar slopes (blood agar base no. 2 [Oxoid Ltd., London, England]) overlaid with Trypticase soy broth and incubated at $30^{\circ} \mathrm{C}$ in air for 3 days. The reference strains were cultured at $37^{\circ} \mathrm{C}$ in air containing $10 \% \mathrm{CO}_{2}$ in semisolid brucella broth (Difco Laboratories, Detroit, Mich.) containing $0.075 \%$ agar. After 2 days of growth, the broth cultures were inoculated onto agar slopes overlaid with brucella broth and incubated at $37^{\circ} \mathrm{C}$ in $10 \%$ $\mathrm{CO}_{2}$ for 3 days. The cells were harvested and centrifuged at $20,000 \times g$ for $30 \mathrm{~min}$. The resulting deposits were washed three times with sterile saline, and then each was suspended to a concentration of $250 \mathrm{mg} / \mathrm{ml}$.

Extraction of protein fraction from bacterial cells. AP extracts were prepared by the method of Morris and Park (10) and stored at $-20^{\circ} \mathrm{C}$ in $0.5-\mathrm{ml}$ portions.

Efiect of growth conditions and age of culture on electrophoretic patterns. The effect of growth conditions on the electrophoretic patterns of AP extracts 
TABLE 1. Campylobacter reference cultures used ${ }^{a}$

\begin{tabular}{|c|c|c|}
\hline Strain & Source $^{b}$ & Origin \\
\hline $\begin{array}{l}\text { C. fetus subsp. } \\
\text { fetus } 12351\end{array}$ & M.S.U. & Ovine fetus \\
\hline $\begin{array}{l}\text { C. fetus subsp. } \\
\text { fetus } \mathrm{B} / 1672\end{array}$ & V.R.L. & Bovine feces \\
\hline $\begin{array}{l}\text { C. fetus subsp. } \\
\text { venerealis } 10354\end{array}$ & N.C.T.C. & $\begin{array}{l}\text { Bovine vaginal } \\
\text { mucus }\end{array}$ \\
\hline C. coli 70.80 & C.I.P. & Porcine feces \\
\hline C. jejuni 70.2 & C.I.P. & Bovine feces \\
\hline $\begin{array}{l}\text { C. sputorum subsp. } \\
\text { sputorum } 53.103\end{array}$ & C.I.P. & Bull semen \\
\hline $\begin{array}{l}\text { C. sputorum subsp. } \\
\text { bubulus } 10355\end{array}$ & N.C.T.C. & Bull semen \\
\hline $\begin{array}{l}\text { C. sputorum subsp. } \\
\text { mucosalis } 982\end{array}$ & E.U. & Porcine intestine \\
\hline
\end{tabular}

${ }^{a}$ See Fig. 1 and 4.

$b$ N.C.T.C., National Collection of Type Cultures, London, England; C.I.P., Collection of the Institut Pasteur, Paris, France; M.S.U., B. D. Firehammer, Montana State University, Bozeman; E.U., G. H. K. Lawson, Edinburgh University, Edinburgh, Scotland.

was studied by using aerotolerant Campylobacter strain $B / 600$, which grew under the conditions used for both the aerotolerant and reference campylobacter strains. Cells were produced under the regime used for the aerotolerant and reference strains, as described above. The effect of age of culture on the electrophoretic patterns was established by using cells of a reference strain and a recent isolate of $C$. fetus subsp. fetus prepared as described above.

Vertical slab gel preparation. Slab gels $(16 \mathrm{~cm}$ by 18 $\mathrm{cm}$ by $1.5 \mathrm{~mm}$ ) were prepared by the method of Morris and Park (10), but they were modified by increasing the concentration of acrylamide from 7.5 to $10 \%$. The gels were made by adding $36 \mathrm{ml}$ of solution $\mathrm{A}(10 \mathrm{~g}$ of acrylamide, $0.275 \mathrm{~g}$ of $N, N^{\prime}$-methylenebisacrylamide, $30 \mathrm{~g}$ of urea, $35 \%$ [vol/vol] aqueous acetic acid to 100 $\mathrm{ml}$ ) to $10 \mathrm{mg}$ of ammonium persulfate and $0.12 \mathrm{ml}$ of $N, N, N, N^{\prime}$-tetramethylenediamine and then pouring this preparation into a vertical slab gel mold (LKB, Uppsala, Sweden). A $75 \%$ acetic acid solution was layered on top of the gel to ensure that a straight edge was formed during polymerization, which was carried out at $37^{\circ} \mathrm{C}$ for $90 \mathrm{~min}$. A stacking gel was prepared by adding $9 \mathrm{ml}$ of solution $B(4.5 \mathrm{ml}$ of solution $A, 4.5 \mathrm{ml}$ of $35 \%$ acetic acid) to $7 \mathrm{mg}$ of ammonium persulfate and $0.1 \mathrm{ml}$ of $N, N, N^{\prime}, N^{\prime}$-m-tetramethylenediamine. A slot former was inserted, and polymerization was carried out at $37^{\circ} \mathrm{C}$ for $90 \mathrm{~min}$, after which the slot former was carefully removed and the sample wells were thoroughly washed with $10 \%$ acetic acid.

Electrophoresis. A $10 \%$ acetic acid solution was added to the upper and lower reservoirs of a vertical electrophoresis unit (LKB). AP extracts containing 100 to $150 \mu \mathrm{g}$ of protein were applied to the wells through the reservoir fluid with a microsyringe. The upper electrode was used as the anode, and the gels were run at a constant current of $50 \mathrm{~mA} / \mathrm{gel}$ for $2.5 \mathrm{~h}$ at $8^{\circ} \mathrm{C}$. The gels were then stained with Coomassie blue for $30 \mathrm{~min}$ at $22^{\circ} \mathrm{C}$ and destained with a methanolacetic acid-water mixture (7). Photographs of each gel were made as permanent records.

\section{RESULTS}

Effect of growth conditions and age of culture on electrophoretic protein profiles. Figure 1 shows that AP extracts of Campylobacter strain $B / 600$ grown under different conditions gave identical electrophoretic protein profiles (Fig. 1, lanes a to d). The extracts prepared from the reference strain and the recent isolate of $C$. fetus subsp. fetus demonstrated identical profiles (Fig. 1, lanes e and f).

Polyacrylamide gel protein profiles of the aerotolerant Campylobacter isolates. Of 41 aerotolerant Campylobacter isolates, 38 (92.5\%) demonstrated very similar electrophoretic protein profiles, and therefore only representative results are shown in Fig. 2. Figure 2, lanes a to d show the patterns of aerotolerant Campylobacter strains isolated from aborted fetuses; lane $\mathrm{e}$ shows the pattern of a strain isolated from the placenta of an aborted cow, and lanes $f$ and $g$ show the patterns of strains isolated from a normal bovine placenta and fetus, respectively. The patterns usually consisted of 20 bands, and there were 2 major components. There was some variation in the staining intensities of the various bands, including bands with identical electrophoretic mobilities. Figure 3 shows the patterns of the three aerotolerant Campylobacter isolates (Fig. 3, lanes a to c) which differed from the majority of the aerotolerant strains (lane d). Isolates $A / 49$ and $A / 22$ (Fig. 3, lanes a and $b$, respectively) were quite similar, although not identical. Strain B/600 (Fig. 3, lane c) produced a pattern very similar to the patterns of

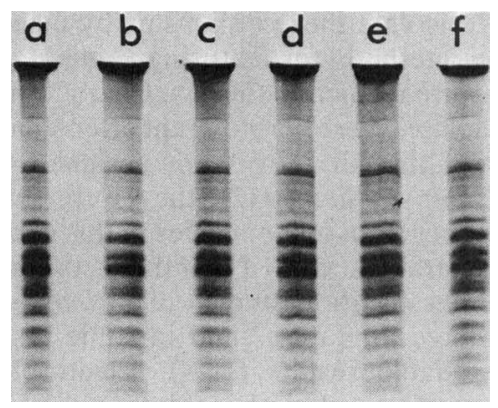

FIG. 1. Comparison of AP extracts in $10 \%$ vertical slab gels. Lane a, Strain B/600 grown aerobically at $30^{\circ} \mathrm{C}$ on blood agar base no. 2 with a brucella broth overlay; lane $b$, strain $B / 600$ grown aerobically on blood agar base no. 2 with a Trypticase soy broth overlay; lane c, strain $\mathrm{B} / 600$ grown in $10 \% \mathrm{CO}_{2}$ in air at $37^{\circ} \mathrm{C}$ on blood agar base no. 2 with a brucella broth overlay; lane d, strain $\mathrm{B} / 600$ grown in $10 \% \mathrm{CO}_{2}$ in air on blood agar base no. 2 with a Trypticase soy broth overlay; lane e, reference strain $C$. fetus subsp. fetus 12351 ; lane $f$, strain $B / 1672$, a recent isolate of $C$. fetus subsp. fetus. The gel was stained with Coomassie blue. 


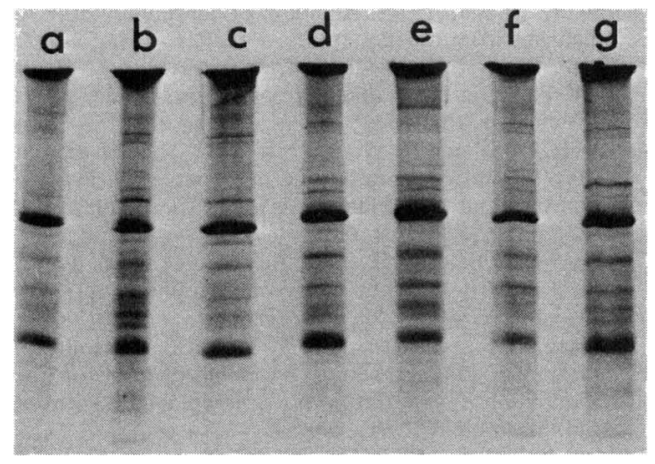

FIG. 2. Comparison in $10 \%$ vertical slab gels of AP extracts of aerotolerant Campylobacter isolates from aborted and nonaborted material. Isolates were obtained from an aborted bovine fetus (lane a), an aborted porcine fetus (lane b), an aborted ovine fetus (lane c), an aborted equine fetus (lane d), the placenta of an aborted bovine (lane e), the placenta of a nonaborted bovine (lane $\mathrm{f}$ ), and a nonaborted bovine fetus (lane g). The gel was stained with Coomassie blue.

the $C$. fetus subsp. venerealis and $C$. fetus subsp. fetus strains examined (Fig. 4, lanes $g$ and $h$ ).

Comparison of aerotolerant Campylobacter isolates with reference Campylobacter strains. As Fig. 4 shows, a representative sample of the aerotolerant Campylobacter isolates studied (Fig. 4, lane a) appears to be quite distinct from all of the reference strains examined. $C$. sputorum subsp. sputorum (Fig. 4, lane b) and $C$. sputorum subsp. bubulus (lane c) had identical

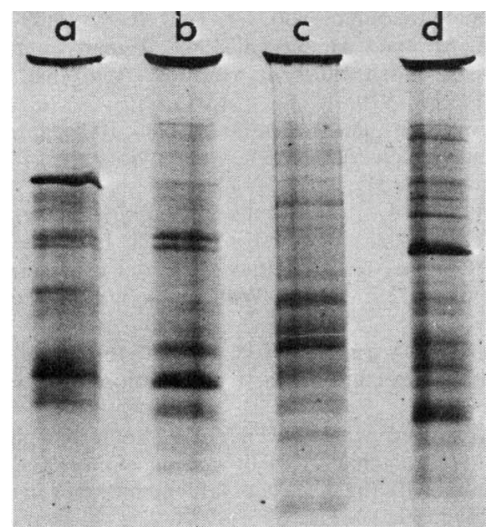

FIG. 3. Comparison in $10 \%$ vertical slab gels of AP extracts of those aerotolerant Campylobacter isolates which differed from the main group. Lane a, Strain $A / 49$ from an aborted porcine fetus; lane $b$, strain $A / 22$ from an aborted porcine fetus; lane $c$, strain $B / 600$ from an aborted bovine fetus; lane d, reference sample from the main group of aerotolerant Campylobacter isolates. The gel was stained with Coomassie blue. patterns, which differed from that of $C$. sputorum subsp. mucosalis (lane d). C. sputorum subsp. mucosalis, C. coli (lane e), and C. jejuni (lane f) generally produced individually distinct patterns. C. fetus subsp. venerealis (lane g) and C. fetus subsp. fetus (lane h) had identical patterns, which differed from the patterns of $C$. jejuni and the other strains examined. It was obvious that although there were differences between the patterns of the aerotolerant Campylobacter isolates and those of the reference strains, there were several bands with common electrophoretic mobilities.

\section{DISCUSSION}

In agreement with other workers $(9,14)$, we found that the different growth conditions used to produce bacterial cells did not affect the composition of the electrophoretic protein profiles (Fig. 1), thus permitting a valid comparison between the aerotolerant Campylobacter isolates and reference strains. The electrophoretic patterns obtained by using recent isolates of $C$. fetus subsp. fetus were identical to those of the corresponding reference strains. This indicated that the age of a culture and storage apparently did not affect the reproducibility of Campylobacter electrophoretic patterns.

It has been reported previously (10) that marked differences demonstrated by electrophoresis among bovine, porcine, and ovine isolates of Campylobacter indicate that pigs are unlikely to serve as a source of infection for cattle and sheep and vice versa. We believe that this does not apply to the aerotolerant Campylobacter isolates examined in this study, as the electrophoretic patterns of these isolates were very similar irrespective of origin. Like other workers (10), we were unable to differentiate between

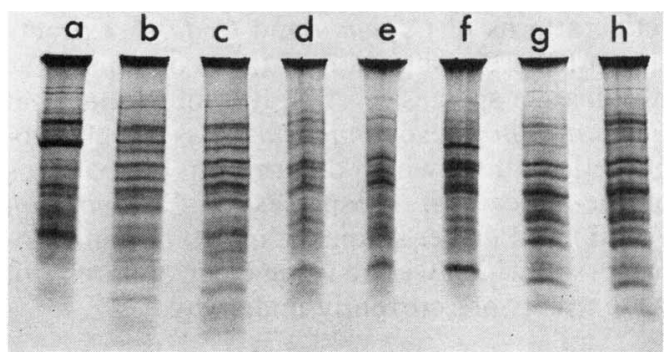

FIG. 4. Comparison in $10 \%$ vertical slab gels of AP extracts of an aerotolerant Campylobacter isolate and Campylobacter reference strains. Lane a, Aerotolerant Campylobacter isolate; lane b, $C$. sputorum subsp. sputorum 53.103; lane c, C. sputorum subsp. bubulus 10355; lane d, $C$. sputorum subsp. mucosalis 982 ; lane e, $C$. coli 70.80; lane f, $C$. jejuni 70.2; lane g, $C$. fetus subsp. venerealis 10354 ; lane $h, C$. fetus subsp. fetus 12351. The gel was stained with Coomassie blue. 
isolates recovered from aborted and nonaborted animals. Variation in the intensity of staining within the patterns of the aerotolerant Campylobacter isolates (Fig. 2) provides evidence of a quantitative difference in the various proteins present (13). The three aerotolerant Campylobacter isolates giving electrophoretic protein patterns that were atypical of the main group (Fig. 3) had other different characteristics. Strains $A / 49$ and $A / 22$ were more tolerant of a wide range of inhibitory substances than the main group of aerotolerant Campylobacter isolates (unpublished data). Strain B/600 also differed from the remainder of the group in that it grew in the presence of $1 \%$ glycine and $4 \%$ nalidixic acid, as did C. fetus subsp. fetus (unpublished data). It is interesting that strain $\mathrm{B} / 600$ gave an electrophoretic protein profile identical to the profiles of $C$. fetus subsp. fetus and $C$. fetus subsp. venerealis (Fig. 4, lanes $g$ and $h$ ).

Although the aerotolerant isolates which we examined are assigned to the genus Campylobacter, the typical electrophoretic pattern for these isolates is quite distinct from the pattern of any of the reference strains examined. These findings, combined with the cultural (2), biochemical $(11,12)$, and serological (3) characteristics of the aerotolerant isolates, confirm the uniqueness of this hitherto unrecognized species within the genus Campylobacter.

The results shown in Fig. 4 demonstrate that by using the gel patterns of AP extracts, we can readily differentiate Campylobacter to at least species level. Other workers have successfully applied this technique to the classification of Mycoplasma species (14), Corynebacterium species (6), Brucella species (8), and bacterial isolates of gingival crevice floras (8). AP extraction is thought to solubilize the hydrophobic portions of membrane proteins (21), which may be used as a measurement of genetic relatedness (15). The marked differences in the electrophoretic patterns of $C$. jejuni and $C$. fetus extracts support the classification of these organisms as two distinct species $(17,22)$. It is interesting that C. sputorum subsp. mucosalis has an electrophoretic pattern which differs from the patterns of the other two subspecies of $C$. sputorum examined. Further studies of intestinal campylobacters in which we are using electrophoresis of AP extracts are currently underway.

\section{ACKNOWLEDGMENT}

We thank V. Smyth for excellent technical assistance.

\section{LITERATURE CITED}

1. Chang, W. E., and J. E. Ogg. 1971. Transduction and mutation of glycine tolerance in Vibrio fetus. Am. J. Vet. Res. 32:649-653.

2. Ellis, W. A., S. D. Neill, J. J. O'Brien, H. W. Ferguson, and J. Hanna. 1977. Isolation of spirillum/vibrio like organisms from bovine fetuses. Vet. Rec. 100:451-452.

3. Ellis, W. A., S. D. Neill, J. J. O'Brien, and J. Hanna. 1978. Isolation of spirillum like organisms from pig fetuses. Vet. Rec. 102:106.

4. Fernie, D. S., and R. W. A. Park. 1977. The isolation and nature of campylobacters (microaerophilic vibrios) from laboratory and wild rodents. J. Med. Microbiol. 10:325329.

5. Jakovljevic, D., and H. E. R. Beattie. 1966. Characteristics of growth of some Vibrio fetus strains in semi-solid nutrient agar. Aust. Vet. J. 42:396.

6. Larsen, S. A., S. T. Bickman, T. M. Buchanan, and W. L. Jones. 1971. Polyacrylamide gel electrophoresis of Corynebacterium diphtheriae: a possible epidemiological aid. Appl. Microbiol. 22:885-890.

7. McNulty, M. S., E. J. Gowans, M. J. Houston, and G. Frazer. 1975. Neuraminidase content of strains of Newcastle disease virus which differ in virulence. J. Gen. Microbiol. 29:399-402.

8. Moore, W. E. C., D. E. Hash, L. V. Holdeman, and E. P. Cato. 1980. Polyacrylamide slab gel electrophoresis of soluble proteins for studies of bacterial floras. Appl. Environ. Microbiol. 39:900-907.

9. Morris, J. A. 1973. The use of polyacrylamide gel electrophoresis in taxonomy of Brucella. J. Gen. Microbiol. 76:231-237.

10. Morris, J. A., and R. W. A. Park. 1973. A comparison using gel electrophoresis of cell proteins of campylobacters (vibrios) associated with infertility, abortion and swine dysentery. J. Gen. Microbiol. 78:165-178.

11. Neill, S. D., W. A. Ellis, and J. J. O'Brien. 1978. The biochemical characteristics of campylobacter like organisms from cattle and pigs. Res. Vet. Sci. 25:368-372.

12. Neill, S. D., W. A. Ellis, and J. J. O'Brien. 1979. Designation of aerotolerant campylobacter like organisms from porcine and bovine abortions to the genus Campylobacter. Res. Vet. Sci. 27:180-186.

13. Odom, R. 1966. Quantitation in protein electrophoresismethods, p. 42-52. In S. T. Nerenberg (ed.), Electrophoresis-a practical laboratory manual. F. A. Davis Co., Philadelphia.

14. Razin, S., and S. Rottem. 1967. Identification of Mycoplasma and other organisms by polyacrylamide gel electrophoresis of cell proteins. J. Bacteriol. 94:1807-1810.

15. Sacks, T. G., H. Haas, and S. Razin. 1969. Polyacrylamide gel electrophoresis of cell proteins of Enterobacteriaceae. A possible taxonomic aid. Isr. J. Med. Sci. 5:49-55.

16. Sebald, M., and M. Veron. 1963. Teneur en bases de l'ADN et classification de vibrions. Ann. Inst. Pasteur Paris 105:897-910.

17. Skirrow, M. B., and J. Benjamin. 1980. 1001 campylobacters: cultural characteristics of campylobacters from man and animal. J. Hyg. 85:427-442.

18. Smibert, R. M. 1974. Genus II. Campylobacter Sebald and Véron 1963, 907, p. 207-212. In R. E. Buchanan and N. E. Gibbons (ed.), Bergey's manual of determinative bacteriology, 8th ed. The Williams \& Wilkins Co., Baltimore.

19. Smith, T. 1918. Spirilla associated with disease of the fetal membranes in cattle (infectious abortion). J. Exp. Med. 28:701-719.

20. Smith, T., and M. S. Taylor. 1919. Some morphological and biological characters of spirilla (Vibrio fetus NSP) associated with the disease of fetal membranes in cattle. J. Exp. Med. 30:299-311.

21. Takayama, K., D. H. MacLennon, A. Tzagolof, and C. D. Stoner. 1966. Studies on the electron transfer system. LXVII. Polyacrylamide gel electrophoresis of the mitochondrial electron transfer complexes. Arch. Biochem. Biophys. 114:223-240.

22. Veron, M., and R. Chatelain. 1973. Taxonomic study of the genus Campylobacter. Int. J. Syst. Bacteriol. 23:122134 . 